\title{
Identification of trace metal speciation in environment using Z-contrast imaging
}

\section{S. UTSUNOMIYA}

Department of Geological Sciences, University of Michigan, Ann Arbor, Michigan 48109-1063 USA. (utu@umich.edu)

A major challenge to understanding the fate of contaminants in environment is the direct identification of trace concentrations (ppm to $\mathrm{ppb}$ ) at the sub-micron scale. In order to efficiently characterize the trace metals in various environmental and geological samples, we have utilized high-angle annular darkfield scanning transmission electron microscopy (HAADFSTEM) combined with conventional TEM techniques. In general, the image contrast observed in the HAADF-STEM is correlated to the atomic mass: heavier elements contribute to a brighter contrast. Additionally, the contrast in HAADF-STEM is characteristically independent of focus, because the image is formed by incoherent scattering. Remarkable results obtained using the advanced TEM technique are shown as an example.

(i) Fine- and ultra-fine particles with heavy metals in urban aerosols from various locations were examined to investigate metal concentrations and speciation. The trace element speciation: $\mathrm{Pb}, \mathrm{As}, \mathrm{Sb}, \mathrm{La}, \mathrm{Ce}, \mathrm{Sr}, \mathrm{Zn}, \mathrm{Cr}, \mathrm{Se}, \mathrm{Sn}, \mathrm{Y}, \mathrm{Zr}, \mathrm{Au}, \mathrm{Ag}$ and $U$ have been characterized. We have identified nanocrystals of uraninite encapsulated in carbonaceous matter $(\sim 50 \mathrm{~nm})$. The "carbon-caged" nanocrystals of uraninite are protected from the immediate oxidation that would lead to increased mobility of uranium in the environment. Still, the presence of uranium in the very fine-fraction $\left(\mathrm{PM}_{2.5}\right)$ of atmospheric particulates provides another pathway for radiation exposure [1].

(ii) A direct, near atomic-scale characterization of $\mathrm{Pb}$ is demonstrated in zircon (3.3-4.4 Ga). Two forms of $\mathrm{Pb}$ have been identified: $\mathrm{Pb}$ concentrated at $\sim 3$ atom $\%$ as a nanoscale patch in zircon structure, and $\mathrm{Pb}$ concentrated within the amorphous domain created by fission fragment damage. The first result suggests that the $\mathrm{Pb}$ atoms directly substitute for $\mathrm{Zr}^{4+}$ in the zircon structure, and the latter observation demonstrates that $\mathrm{Pb}$ diffusion can occur through amorphous regions created by radiation damage, although volume diffusion is typically considered to be the dominant diffusion mechanism for $\mathrm{Pb}$. Beyond the first percolation point, i.e., when the amorphous domains overlap and form a fully interconnected network, there is a new fast pathway for the diffusion of $\mathrm{Pb}$ [2].

These examples illustrate the value of HAADF-STEM as a powerful technique for the direct investigation and identification of trace elements in nano-scale particles. This is a particularly useful technique for the relatively heavy metals that occur at extremely low bulk concentrations (ppb to $\mathrm{ppm}$ ) in a lighter element matrix [3].

References

[1] Utsunomiya S., Jensen K.A., Keeler G.J., Ewing R.C., Environ. Sci. Technol. 36, 4943-4947.

[2] Utsunomiya S., Palenik C.S., Valley J.W., Cavosie, A.J., Wilde, S.A., Ewing R.C., Geochim.Comochim Acta. 68, 4679-4686.

[3] Utsunomiya S., Ewing R.C., Environ. Sci. Technol. 37, 786791. 